\title{
Conditioned social aversion in young male Mongolian gerbils (Meriones unguiculatus)
}

\author{
TERRY F. PETTIJOHN and BRUCE LOZANOFF \\ The Ohio State University, Marion, Ohio 43302
}

\begin{abstract}
The current study was designed to determine if conditioned social aversion could be extended to young gerbils. Forty young 3-month-old male Mongolian gerbils were tested with an unfamiliar 3-month-old conspecific for two 5-min sessions $48 \mathrm{~h}$ apart. The experimental subjects received an injection of $\mathrm{LiCl}$ immediately after the first session, while the control subjects received saline. Investigation duration and approach frequency significantly decreased for the experimental subjects. The research demonstrated that naive young male gerbils were capable of forming social aversions.
\end{abstract}

A large number of studies on conditioned taste aversion have been reported in the literature in recent years (Riley \& Baril, 1976). Several researchers have attempted to extend the findings of taste aversion experiments to social settings. Zahorik and Johnston (1976) reported that hamsters formed a taste aversion to a socially relevant stimulus. After exposing the subjects to female hamster vaginal secretions on a glass slide, they induced gastrointestinal illness by injection of $1 \%$ body weight of $.2 \mathrm{M}$ lithium chloride. When retested $48 \mathrm{~h}$ later, the male hamsters showed significantly less approach to and licking of the vaginal test secretions. Johnston, Zahorik, Immler, and Zakon (1978) extended this finding by reporting that after experiencing the pairing of vaginal secretions with illness, male hamsters show less sexual behavior when presented with an estrus female. This line of research has important potential for the investigation of taste/odor communication in animal social organizations.

The Mongolian gerbil is a particularly good animal in which to test the effectiveness of conditioned aversion techniques in altering social behavior. Studies have shown that gerbils spend a great deal of time socially investigating one another when paired for a test observation (Christenson, Wallen, Brown, \& Glickman, 1973; Halpin, 1974, 1976; Martindale \& Hines, 1977; Swanson, 1974). Numerous studies have demonstrated that gerbils can identify relevant social odors (Dagg \& Windsor, 1971; Halpin, 1974, 1976).

Several studies have shown that aversions can be learned by gerbils. Kanarek, Adams, and Mayer (1975) reported that gerbils could learn aversions to tastes quickly. Pettijohn (1979) found that male gerbils could easily form an aversion to phenylacetic

This research was supported, in part, by a faculty research grant from the Ohio State University College of Social and Behavioral Sciences. Requests for reprints may be sent to Terry F. Pettijohn, Department of Psychology, Morrill Hall, The Ohio State University, 1465 Mt. Vernon Avenue, Marion, Ohio 43302. acid. Pettijohn and Jamora (1980) reported that gerbils could form an aversion to bedding soiled by unfamiliar conspecifics if given a toxin immediately after exposure. And, recently, Pettijohn (1981) reported a series of studies which demonstrated that adult male gerbils could form a conditioned social aversion to a young male conspecific. The developmental aspects of this paradigm have not been studied in gerbils.

Although the majority of conditioned taste aversion research has been conducted using adult animals, there have been a number of studies which have used young animals. Most of these studies on young animals have had to use extremely young subjects in order to obtain any differences between them and older animals. An early study by Grote and Brown (1971) found that 20-day-old rats could easily be trained in one trial to avoid a lithium chloride solution. Other researchers (Baker, Baker, \& Kesner, 1977; Gregg, Kittrell, Domjan, \& Amsel, 1978) found that young rats could learn taste aversions, but only with short taste-illness delays. Kalat (1975) reported that infant guinea pigs could learn a taste aversion.

Rozin and Kalat (1971) argued that evolutionary forces determine an animal's capacity for learning. If so, then it could be expected that learning would be shown early in the animal's life. Since the ability to learn to avoid poisons has definite advantages, the finding of taste aversion learning in young animals seems reasonable. The purpose of the current experiment was to determine whether social aversions could be learned by young gerbils.

\section{METHOD}

\footnotetext{
Subjects

The subjects for this experiment consisted of $\mathbf{4 0}$ young experimentally naive male Mongolian gerbils (Meriones unguiculatus), 3 months old at testing. All the subjects were reared in opaque plastic laboratory cages $(48 \times 27 \times 20 \mathrm{~cm})$. The cage floor was covered with Absorb-Dri wood-chip bedding, and Purina Lab Chow
} 
and water were available ad lib. Forty male 3-month-old conspecifics served as stimulus animals for the experiment. Prior to the beginning of testing, all subjects and all stimulus animals were isolated in small plastic laboratory cages $(20 \times 30 \times 20 \mathrm{~cm})$ in order to reduce possible confounding due to group odors.

\section{Apparatus}

All testing was conducted in a 1-m-square open field, divided, by black lines on the floor, into $2520 \times 20 \mathrm{~cm}$ sections.

\section{Procedure}

Each of the $\mathbf{4 0}$ subjects was paired with a different unfamiliar 3-month-old male conspecific (the stimulus animal) for two 5-min sessions $48 \mathrm{~h}$ apart. The subject and stimulus animal were placed in the open field $25 \mathrm{~cm}$ apart and facing each other.

During each test session, the following measures were recorded: the total duration (in seconds) of social investigation during which the subject was sniffing or nosing some part of the stimulus animal's body; the frequency of approach in which the subject made contact with the stimulus animal; the latency (in seconds) to the first social contact and the latency from the first social contact to the second social contact; and the frequency of approach to the subject by the stimulus animal.

Half of the subjects formed the experimental group, and the rest were control subjects. Immediately after the first test session (Session 1), the experimental subjects were given an intraperitoneal (ip) injection of $.03 \mathrm{ml} / \mathrm{g}$ body weight of $.15 \mathrm{M}$ lithium chloride (LiCl) in saline. After Session 1, the control group received an equivalent amount of physiological saline. Then each subject was placed back into its own isolation cage. The open field was cleaned with an alcohol solution after each test session. After $48 \mathrm{~h}$, each subject was retested for a second 5-min session (Session 2) in the open field, with the same stimulus animal it had been paired with for Session 1.

\section{RESULTS}

The subjects quickly approached the stimulus animal in Session 1 and began investigating. The subjects generally approached frequently, and spent several seconds investigating the stimulus at each approach. In Session 2, the control (saline) subjects' behavior was similar, but the experimental (lithium) animals behaved very differently. The experimental subjects reduced the frequency of approaches by one half and decreased the duration of investigation also by one half. The experimental subjects appeared to be afraid of the stimulus animal, often avoiding it and spending time alone in the corner.
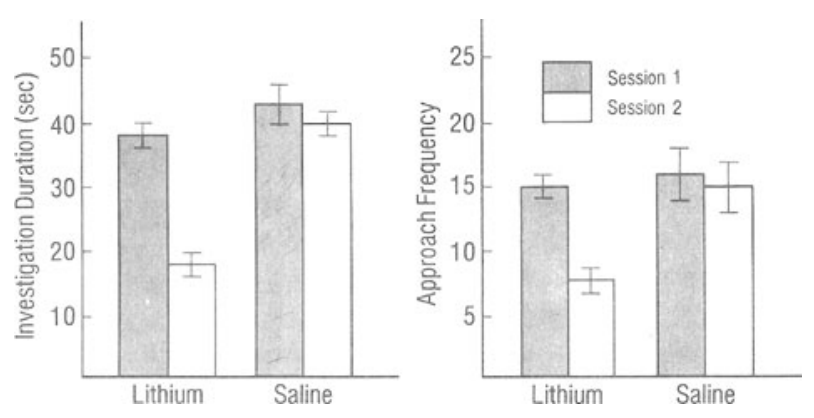

Figure 1. Mean ( \pm SEM) investigation duration (seconds) and mean $( \pm$ SEM) approach frequency for each experimental condition.
For each dependent measure, a $2 \times 2$ analysis of variance was run on drug (lithium or saline) $\times$ session (Session 1 and Session 2), with repeated measures on the last factor. Cicchetti's (1972) extension of the Tukey post hoc test was used to further test significant interactions. Figure 1 shows the mean ( \pm SEM) duration (in seconds) of social investigation of the stimulus animals by the subjects. Duration of investigation was significant for the drug $[F(1,38)=20.4$, $\mathrm{p}<.001]$ and session $[\mathrm{F}(1,38)=62.9, \mathrm{p}<.001]$ factors and for the drug $\times$ session interaction $[F(1,38)=$ 41.6, $\mathrm{p}<.001]$. The Cicchetti test showed the experimental subjects' scores in Session 2 to be significantly $(p<.01)$ different from both their own scores in Session 1 and the control subjects' scores in Session 2. As can be seen in Figure 1, the experimental subjects' scores decreased $51 \%$ in Session 2.

Figure 1 also shows the mean $( \pm S E M)$ frequency of contact approach to the stimulus animal. Again, the differences were significant for the drug $[F(1,38)$ $=21.22, \mathrm{p}<.001]$ and session $[\mathrm{F}(1,38)=34.34$, $\mathrm{p}<.001]$ factors and for the drug $\times$ session interaction $[F(1,38)=24.59, p<.001]$. The Cicchetti test showed the experimental subjects' scores in Session 2 to be significantly $(p<.01)$ different from their own scores in Session 1 and from the control subjects' scores in Session 2.

Figure 2 shows the mean time between placement of the subject in the open field and the first social contact made by the subject. There were no significant differences for latency to the first contact. Figure 2 also shows the mean time between first contact and second contact. Here there were significant differences in the drug $[F(1,38)=10.05, p<.01]$ and session $[F(1,38)=11.14, p<.01]$ factors and drug $\times$ session interaction $[F(1,38)=10.11, p<.01]$. The Cicchetti test found the experimental subjects' scores in Session 2 to be significantly $(p<.01)$ different from the scores of the experimental subjects in Session 1 and the control subjects in Session 2.

The 3-month-old stimulus animals made a mean of 14.14 approaches to the subject during any 5 -min test session. There were no significant differences on either the drug or session factors for approach by the stimulus animal.

\section{DISCUSSION}

This study demonstrated that conditioned social aversion (CSA) was possible in young male Mongolian gerbils if the subjects were made ill immediately after a brief 5-min social encounter. The results agree with the findings of previous research in this laboratory (Pettijohn, 1981), which has concentrated on adult animals. The current results clearly show that young gerbils decrease dramatically their investigation of a stimulus animal that was present before the poison was administered. 

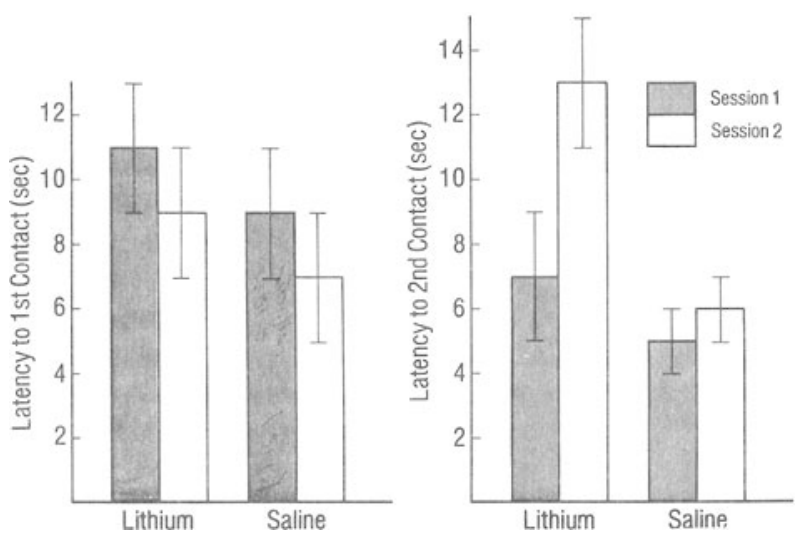

Figure 2. Mean ( \pm SEM) latency to first contact (seconds) and mean ( \pm SEM) latency to second contact (seconds) for each experimental condition.

It is interesting to note that, in the current experiment, the young gerbils spent around $40 \mathrm{sec}$ investigating the stimulus animals in Session 1. Adult male gerbils typically spend around $60 \mathrm{sec}$ in a 5 -min test session. This suggests that gerbils become more socially motivated as they develop. Although it might be predicted that this higher investigation rate would make it more difficult for adults to form an aversion (learned safety hypothesis), this clearly was not the case. Both young and old male gerbils learn social aversions with relative ease.

The current finding that 3-month-old gerbils are capable of forming social aversions to other unfamiliar young conspecifics suggests that the ability to identify and interact with other individuals is an important function for gerbils. The data support the idea of Rozin and Kalat (1971) that evolutionary forces work to prepare an animal to learn what it needs to survive in its natural environment. This suggests that gerbils do not need extensive experience and maturation to form aversions. Thus, the finding supports the view that aversion learning is a general learning process rather than a unique phenomenon.

The current study demonstrated that conditioned social aversion is possible in young gerbils. It did not find any deficit in effectiveness of the young gerbils to form aversions. However, it did not test toxin delay or generalization of CS. Other researchers (Baker, Baker, \& Kesner, 1977; Gregg, Kittrell, Domjan, \& Amsel, 1978) found that the chief difference between adults and young animals in forming taste aversions was the inability of the young to learn with long intervals before toxin administration. This possibility for social aversions needs to be examined.

Through research of this type, scientists are able to gain a better understanding of the sensory cues involved when gerbils interact in social attraction and avoidance behaviors. With the knowledge that young gerbils are as proficient as old animals in forming social aversions, future research can concentrate on understanding the specific mechanisms involved in the learning capability as involved in gerbil social systems.

\section{REFERENCES}

Baker, L., Baker, T., \& Kesner, R. Taste aversion learning in young and adult rats. Journal of Comparative and Physiological Psychology, 1977, 91, 1168-1178.

Christenson, T., Wallen, K., Brown, B., \& Glickman, S. Effects of castration, blindness, and anosmia on social reactivity in the male Mongolian gerbil. Physiology \& Behavior, 1973, 10, 989-994.

Cicchetri, D. V. Extension of the multiple range tests to interaction tables in the analysis of variance. Psychological Bulletin, $1972,77,405-408$.

DAgG, A., \& Windsor, D. Olfactory discrimination limits in gerbils. Canadian Journal of Zoology, 1971, 49, 283-286.

GregG, B., Kittrell, E., Domjan, M., \& Amsel, A. Ingestional aversion learning in preweanling rats. Journal of Comparative and Physiological Psychology, 1978, 92, 785-795.

Grote, F. W., \& Brown, R. T. Rapid learning of passive avoidance by weanling rats: Conditioned taste aversion. Psychonomic Science, 1971, 25, 163-164.

Halpin, Z. Individual differences in the biological odors of the Mongolian gerbil. Behavioral Biology, 1974, 11, 253-259.

HALPIN, Z. The role of individual recognition by odors in the social interactions of the Mongolian gerbil. Behaviour, 1976, 18, 117-130.

Johnston, R., ZAhorik, D., ImmLer, K., \& ZAKon, H. Alterations of male sexual behavior by learned aversion to hamster vaginal secretions. Journal of Comparative and Physiological Psychology, 1978, 92, 85-93.

KalAT, J. Taste aversion learning in infant guinea pigs. Developmental Psychobiology, 1975, 8, 383-387.

Kanarek, R. B., Adams, K. S., \& Mayer, J. Conditioned taste aversion in the Mongolian gerbil. Bulletin of the Psychonomic Society, 1975, 6, 303-305.

Martindale, C., \& Hines, D. Effects of amphetamine and Nembutal on social exploration in the Mongolian gerbil. Pharmacology, Biochemistry and Behavior, 1977, 7, 573-574.

Petrijohn, T. F. Conditioned olfactory aversion in the male Mongolian gerbil. Physiological Psychology, 1979, 7, 299-302.

Petrijohn, T. F. Conditioned social aversion in the male Mongolian gerbil. Journal of Comparative and Physiological Psychology, 1981, 95, 228-239.

Pettijohn, T. F., \& Jamora, C. Learned aversion to soiled bedding in male Mongolian gerbils. Physiology \& Behavior, 1980, 24, 1031-1034.

Riley, A. L., \& BARIL, L. L. Conditioned taste aversions: A bibliography. Animal Learning \& Behavior, 1976, 4, 1S-13S.

Rozin, R., \& Kalat, J. Specific hungers and poison avoidance as adaptive specializations of learning. Psychological Review, $1971,78,459-486$.

Swanson, H. Sex differences in behavior of the Mongolian gerbil in encounters between pairs of same or opposite sex. Animal Behaviour, 1974, 22, 638-644.

ZAhorik, D., \& Johnston, R. Taste aversions to food flavors and vaginal secretion in golden hamsters. Journal of Comparative and Physiological Psychology, 1976, 90, 57-66.

(Manuscript received June 25, 1981; revision accepted for publication August 18, 1981.) 